\title{
Д.И. Петин
}

\section{ЭМИССИЯ ДЕНЕЖНЫХ СУРРОГАТОВ СОВЕТСКОЙ ВЛАСТЬЮ В КЯХТЕ ЛЕТОМ 1918 г.}

\begin{abstract}
На основе выявленного автором и ранее не публиковавшегося комплекса документов (преимущественно из фондов Государственного архива Российской Федерации) проведено подробное исследование одной из самых курьезных региональных эмиссий денежных суррогатов периода Гражданской войны - выпуска бон, осуществленного советской властью летом 1918 г. в небольшом забайкальском городе Кяхта. Дана критика историографии вопроса, и благодаря привлечению новых источников решено имеющееся историографическое противоречие.

Ключевые слова: Гражданская война; советская власть; Кяхта; денежное обращение; денежные суррогаты; бонистика.
\end{abstract}

Первая мировая война и революционные события 1917 г. стали периодом, в котором претерпели существенные изменения практически все ключевые сферы российского государства и общества. Функционирование финансов в Сибири в это сложное для страны время наглядным образом отразило положение дел в экономике и управлении окраинными территориями. При этом отчетливо наблюдалась тенденция: чем больше географически удален регион, тем сильнее проявлялся там кризис денежно-финансовой сферы. В данном случае одновременно показательным и курьезным является опыт вынужденной локальной эмиссии денежных суррогатов, осуществленной в начальный период Гражданской войны Советом народных комиссаров Троицкосавского уезда в Кяхте - небольшом забайкальском городе на границе с Монголией.

Выпуск местных денежных знаков в Кяхте в целом нашел неплохое отражение в историографии денежного обращения в период Гражданской войны. Однако лишь в монографии экономиста и историка дальневосточных финансов А.И. Погребецкого (впервые описавшего эти боны в 1924 г.), а также в статье коллекционера М.С. Сафонова, опубликованной в 1930 г., имеются сведения, существенно освещающие данный вопрос. И в обоих случаях кяхтинская эмиссия упоминается как курьезное явление, произошедшее в общей непростой финансовой ситуации в Забайкалье летом 1918 г. Все последующие публикации (принадлежащие главным образом коллекционерам-бонистам) не вносят в историографию вопроса ничего нового, фактически дублируя информацию, содержащуюся в монографии А.И. Погребецкого.

В фонде Центрального управления Государственного банка Министерства финансов правительства А.В. Колчака (Р-143) в Государственном архиве Российской Федерации автором статьи была выявлена ведомственная переписка, раскрывающая ряд важных подробностей, связанных с выпуском советских бон в Кяхте, а также дальнейшей судьбой эмиссии.

Однако прежде чем перейти к анализу политических и экономических условий появления кяхтинских бон, проведем небольшой экскурс в историю забай- кальских финансов на рубеже 1917-1918 гг. Как бы ни были тяжелы условия, в которых протекала деятельность государственных финансовых учреждений 19141917 гг., но за весь этот период, несмотря на всю трудность почтово-телеграфных и транспортных сообщений с разбросанными по востоку России отделениями Государственного банка и казначействами, работа забайкальских учреждений финансовой сферы оставалась стабильной. Органы местной власти и финансовые учреждения старательно исполняли традиционные порядки организации денежного обращения, ранее установленные Центром [1. С. 15].

Однако во второй половине 1917 г. непростое положение в денежном обращении на территории Сибири повсеместно резко усугубилось. Свою негативную роль имело и ухудшение информационных и транспортных связей Европейской России с Сибирским регионом. В итоге с конца 1917 г. Петроград не имел объективной оперативной информации о деятельности и условиях функционирования финансовых учреждений Востока России [2. С. 34]. Это подталкивало провинциальное руководство к вынужденным самостоятельным действиям чрезвычайного характера.

Одним из общих для всей России и очень болезненных вопросов денежного обращения было снабжение регионов подкреплением. С осени 1917 г. в Сибири отмечалась острая нехватка наличных денежных средств, каковые должны были присылаться из Петрограда. Нараставший денежный дефицит ставил под угрозу удовлетворение государственных и социальных нужд, работу муниципальных хозяйств и транспорта. А эти обстоятельства при условии слабой вертикали власти угрожали общим коллапсом. Получив из Петрограда денежное подкрепление, власти губерний и областей Сибири регулярно решали непростой для себя вопрос: как наиболее рационально распределить полученные деньги? Ситуация вдобавок ко всему имела дополнительную сложность, угрожавшую разменным дефицитом: присылаемые Петроградом суммы наличности содержали крайне ничтожную долю разменных денежных знаков [3. Д. 3А. Л. 96]. 
Особенно тяжёлая и порой тупиковая обстановка в начале 1918 г. стала наблюдаться в восточной части сибирского региона - Забайкальской области. В частности, в Кяхте из-за «разменного голода», катастрофически усугублявшегося с осени 1917 г., приостановились все банковские операции. Это сводило к минимуму местную некогда бойкую торговоэкономическую жизнь. Управляющий Кяхтинским отделением Народного (бывшего Государственного) банка Н.И. Шувалов 13 января 1918 г. направил в Петроград срочную телеграмму. В ней он в категоричной форме ставил вопрос о прекращении деятельности возглавляемого им банковского отделения и закрытии его в связи со сложившимся положением дел. Причиной тупиковой ситуации Н.И. Шувалов называл «отсутствие какой-либо денежной наличности для расчетов с населением» [4. Д. 579. Л. 2].

Однако, если смотреть обобщенно, то задержка присылки денежного подкрепления в Забайкалье из Центральной России и, как следствие, критический недостаток денег в обращении порождались совокупностью двух ключевых причин: саботажем финансовых чиновников в Центре и нарушенными транспортными связями. Причем последнее обстоятельство дополнительно отягощалось географической удалённостью территорий. В итоге отдалённые уезды и города Забайкалья, каковыми и являлись Троицкосавский уезд и входившая в него Кяхта, уже с ноября 1917 г. не получали запрашиваемого денежного подкрепления в необходимом объёме. Как показывает анализ телеграмм Кяхтинского отделения Народного (бывшего Государственного) банка, адресованных в Петроград, в отдел кредитных билетов Народного банка, денежная наличность, заказываемая Кяхтой у Петрограда, приходила либо не в полном объёме, либо с весьма значительным опозданием, составлявшим, как правило, один-два месяца. Особенно дефицитными в Забайкалье были казначейские знаки и деньги-марки с номиналами, исчисляемыми в копейках. Снабжение Забайкалья таковыми купюрами с конца осени 1917 г. не осуществлялось. В упомянутой выше телеграмме управляющий Кяхтинским отделением Народного банка Н.И. Шувалов также сообщал, что для местного населения внезапное исчезновение в Кяхте разменных купюр стало крайне неожиданным явлением. Естественным образом среди населения активное развитие получала спекуляция разменом крупных денежных знаков на мелкие купюры. Появилась и дифференциация денег рынком. Так, «старые» государственные кредитные билеты («романовские») тотчас у местных торговых монополий оказались в неконкурентном предпочтении. А выпущенные Временным правительством государственные кредитные билеты и казначейские знаки образца 1917 г. («думские» и «керенки»), приходившие в подкреплениях из Петрограда, хотя рынком и не отторгались полностью, но ценились ниже и оттого принимались гораздо хуже [Там же. Л. 2, 4, 7].
Однако ключевым «источником» этой проблемы были все же представители местной торговли - главным образом монголы и китайцы, не признававшие новых видов денег. Особенная тревожность в связи с финансовым тупиком была в том, что на юге Забайкалья Кяхта являлась одним из основных пунктов приграничной торговли с Монголией и Китаем. И поэтому всякое нарушение в функционировании денежной сферы негативно сказывалось здесь на товарно-денежных отношениях. Золотая и серебряная монета, а также «романовские» кредитные билеты весьма неплохо котировались в соседней Северной Маньчжурии и на Дальнем Востоке. В связи с этим монгольские и китайские торговцы, продавая свои товары, традиционно стремились брать в расчёт именно эти средства платежа. Таком образом, иностранцы активно формировали приоритеты в виде денежных знаков, употребляемых в местном денежном обращении [Там же. Л. 245; 5. C. 43]. Поэтому в тот период из-за указанных рыночных особенностей все операции с новыми видами денег на территории Забайкальской области, как правило, проходили болезненно (и особенно в приграничной полосе).

Поворотным моментом в дальнейшем развитии отечественной истории стала Гражданская война. Для советской власти в Сибири начавшиеся с лета 1918 г. боевые действия, как в военном, так и в финансово-экономическом отношении, потребовали громадных затрат на ведение борьбы с антибольшевистскими силами. Но практически одновременно нарушенное транспортное сообщение от Урала до Дальнего Востока привело к разрыву связей Центральной России с регионами и усугубило распад единой денежной системы. С началом боевых действий Сибирь уже не получала из Центра денежной наличности. Это наглядно отображается в статистике отправления денежного подкрепления на Восток России в первой половине 1918 г. [6. С. 211]. Последние суммы финансового подкрепления были высланы из Петрограда в период с 16 мая по 1 июня 1918 г. несколькими партиями и в основном в разменных знаках. Суммы направлялись в Омск (60,075 млн руб.), Иркутск (50,065 млн руб.) и Красноярск (15 млн руб.) [4. Д. 868. Л. 32]. Однако по причине военно-политических событий, произошедших на Востоке России на рубеже мая-июня 1918 г., вполне очевидным остаётся вопрос: а дошли ли эти суммы до пунктов, куда они причитались?

Уже в течение июня 1918 г. Западная Сибирь находилась под контролем антибольшевистских сил. До осени 1918 г. в Забайкалье, Амурской области и Приморье областные и уездные Советы защищались от натиска контрреволюции, функционируя фактически в качестве самостоятельных локальных «государственных образований». Большевики при отступлении на восток летом 1918 г., эвакуируя ценности, стремились вывезти всю денежную наличность, хранящуюся в кладовых банков и казначейств, ставя тем самым 
своих политических противников в весьма затруднительное положение. В ряде сибирских городов после оставления их советской властью кассы банковских отделений и казначейств оказались пустыми и разгромленными. Но отступавшие большевики целенаправленно вывозили из финансовых учреждений не только ценности и денежную наличность. Подчас подлежала вывозу и основная финансовая документация [7. С. 16-17, 29, 32]. По оценкам, произведенным в начале 1919 г. уже колчаковскими властями, большевиками при их эвакуации из сибирских городов летом 1918 г. было вывезено запасов денежной наличности более чем на 917 млн руб., до 167 пудов золота и порядка 500 пудов серебра [8. С. 2].

На территории южной части Восточной Сибири в течение лета 1918 г. существовал крупный очаг советской власти, продолжавший бороться, но сдававший позиции под напором антибольшевистских сил. В связи с началом боевых действий и окончательно прерванной присылкой денег из Петрограда большевистские власти Забайкалья оказались в еще более тяжёлом положении. Столкнувшись с острым дефицитом денег в обращении, они были вынуждены вновь искать пути его устранения. А.И. Погребецкий свидетельствует: «Неполучение подкреплений из Центра повлекло в дальнейшем недостачу и в крупных купюрах, а денежное обращение в целом подверглось значительной депрессии. Совет Читинского отделения Народного банка Второго созыва на заседании 25 июня 1918 г., заслушав сообщение о денежном кризисе в Забайкальской области, постановил: 1. Находящиеся в портфеле пятипроцентные обязательства Государственного казначейства истекших сроков выпустить в обращение наравне с кредитными билетами, согласно декрету 21 января 1918 г. 2. Уведомить об этом комиссара финансов, казначейства и национализированные частные кредитные учреждения, а также напечатать соответствующие объявления в местных газетах» [9. С. 241242; 10. Д. 117. Л. 117].

Кяхта, как центр экономической жизни Троицкосавского уезда Забайкальской области, в очередной раз испытывала финансовый коллапс, вызванный теперь уже полным прекращением поступления наличных денег из Петрограда. Крупных купюр в обращении было еще достаточно. Имевшиеся в обращении «керенки» принимались населением, однако по масштабам цен купюры в 20 и 40 руб. для расчётов велики, была очевидна необходимость разменных банкнот. Кризисная ситуация, вызванная «разменным голодом», в июне 1918 г. достигла своего апогея. И, как показывает общероссийская практика того времени, единственным возможным выходом из данной ситуации стало осуществление локальной эмиссии.

Нет сведений о том, кто именно инициировал выпуск кяхтинских бон. Но, исходя из анализа документов, с высокой долей вероятности мы можем утверждать, что это, по всей видимости, было компромисс- ное решение уездных и городских советских властей и финансово-хозяйственных органов. Обоюдная заинтересованность в решении вопроса была очевидна. В результате, согласно постановлению Совета народных комиссаров Троицкосавского уезда от 19 июня 1918 г., «ввиду острой нужды в мелких денежных знаках и совершенной оторванности от Центра» началась подготовка к выпуску бон через Кяхтинское отделение Народного банка. Для организации и контроля над проведением эмиссии была создана специальная комиссия. Она состояла из представителей уездной советской администрации и финансовых учреждений. В комиссию, в частности, вошли: А.М. Малофеев (уездный комиссар финансов), В.И. Ермоленко (исполнявший обязанности управляющего Кяхтинским отделением Народного банка), И.О. Дидковский (исполнявший обязанности контролера Кяхтинского отделения Народного банка), А.Д. Бруевич (кассир Кяхтинского отделения Народного банка), П.П. Обухов (помощник кассира Кяхтинского отделения Народного банка), Н.М. Смирнов (делегат от отдела городского хозяйства), А.Р. Павловский (комиссар контрольноучетного отдела), Ф.М. Наделяев (казначей Кяхтинского казначейства) и С.М. Немчинов (член учётноссудного комитета) [10. Д. 120. Л. 32, 34-37].

В историографии встречаются искажения при написании фамилий уездного комиссара финансов и управляющего Кяхтинским отделением Народного банка. Приводимые в данной публикации варианты, на наш взгляд, являются правильными, поскольку они были выявлены нами в ходе анализа делопроизводственных источников Центрального управления Государственного банка Министерства финансов правительства А.В. Колчака.

Исполнить местные боны было решено во внешней аналогии с выпущенными в апреле 1918 г. читинскими суррогатами (гербовыми марками). Кяхтинская типография, владельцем которой был А.И. Лушников, произвела заготовление бланков будущих односторонних бон номиналами 5 и 10 руб. за подписью уездного комиссара финансов и управляющего Кяхтинским отделением Народного банка. Печать бланков производилась одной чёрной краской на белой бумаге. Казначейские знаки номиналами 20 и 40 руб. («керенки») в количестве, необходимом для выпуска, были получены по чекам с текущего счёта Троицкосавской городской управы. «Керенки» после разрезки на четыре равных части наклеивались на бланк. После разрезки и наклейки фрагментов «керенок» на каждый бланк проставлялась гербовая печать Кяхтинского отделения Народного банка. Печать ставилась так, чтобы захватить поле денежного знака (во избежание подделки). Затем с помощью нумератора на боны нанесли индивидуальную нумерацию. Денежные суррогаты, уже приобретшие законченный вид, поступили через обратный взнос на текущий счёт Троицкосавской городской управы. После этого они были сразу переданы в разменную кассу для ско- 
рейшего введения в обращение. Неиспользованные бланки бон поместили в огнеупорный ящик под два ключа, находившийся в операционном помещении Кяхтинского отделения Народного банка. Ключи для хранения (в целях контроля доступа) получили только два лица: это представитель отдела городского хозяйства Н.М. Смирнов и уездный комиссар финансов А.М. Малофеев. Ящик с неиспользованными бланками бон был опечатан в присутствии уполномоченных сотрудников местного отделения Народного банка и Троицкосавской городской управы [10. Д. 120. Л. 33].
Первый выпуск кяхтинских бон в обращение состоялся через полмесяца после принятия решения о выпуске - 3 июля 1918 г. Аналогичные выпуски бон в целях стабилизации финансовой обстановки были повторены ещё дважды. В результате общий объём советской кяхтинской эмиссии, осуществлённой тремя сериями (3, 6 и 16 июля 1918 г. соответственно), составил 65000 руб. [Там же. Л. 34-36; 11. С. 170]. Выявленные статистические сведения об эмиссии советских бон в Кяхте в обобщенном виде представлены в таблице.

Количественные показатели эмиссии бон, выпущенных Кяхтинским отделением Народного банка в июле 1918 г.*

\begin{tabular}{|c|c|c|c|c|}
\hline Номинал, руб. & $\begin{array}{c}\text { Заготовлено } \\
\text { бланков, шт. }\end{array}$ & $\begin{array}{c}\text { Осталось неиспользованных } \\
\text { бланков, шт. }\end{array}$ & $\begin{array}{c}\text { Выпущено бон, } \\
\text { шт. руб. }\end{array}$ & $\begin{array}{c}\text { Осталось } \\
\text { на руках, руб. }\end{array}$ \\
\hline 5 & 7022 & 1022 & $6000 / 30000$ & 56810 \\
\hline 10 & 8058 & 4558 & $3500 / 35000$ & 80 \\
\hline ВСЕО & 15080 & 5580 & $9500 / 65000$ & 56810 \\
\hline
\end{tabular}

*См: [10. Л. 32-37; 11. С. 172].

Выпуск советских бон в Кяхте не был в противоречии с эмиссионным правом государства. Ведь «обеспечили» эмиссию денежные знаки, уже введенные в обращение [10. Д. 120. Л. 35]. Очевидно, что выпущенные в Кяхте денежные суррогаты по восстановлению в дальнейшем нормальной поставки кассового подкрепления уездные власти планировали обменять, списав «керенки», использованные для производства эмиссии, как ветхие денежные знаки.

В историографии было противоречие относительно времени появления кяхтинских бон. А.И. Погребецкий утверждает, что их эмиссия была осуществлена намного раньше - в марте 1918 г. М.С. Сафонов называет датой принятия решения об осуществлении эмиссии 11 июня 1918 г., временем эмиссии бон он указывает июль 1918 г. Обнаруженные нами документы говорят о правоте М.С. Сафонова. Но, согласно выявленным нами документам, датой принятия решения о выпуске бон было 19 июня 1918 г. [Там же. Л. 33].

В период революции и Гражданской войны на территории бывшей Российской империи были выпущены тысячи денежных суррогатов, но кяхтинские боны можно отнести к числу наиболее оригинальных. По подписи уездного комиссара финансов А.М. Малофеева, стоявшей на бонах, в народе эти платежные средства получили в широком обиходе прозвище «малофеевки». Были и другие варианты неофициальных названий, связанные уже со спецификой внешнего оформления этих бон - «обрезки» или «четвертованные керенки». Кяхтинские боны активно использовались около двух месяцев, после чего из-за роста цен и появления в обращении в августе 1918 г. кредитных билетов Центросибири они потеряли былую экономическую актуальность [9. С. 245-246; 10. Д. 117. Л. 19].

Формально кяхтинские боны, как на них было указано, подлежали приему в платежи на всей территории Забайкальской области. Фактическим ареалом их об- ращения стал Троицкосавский уезд, приграничный Маймачен (Монголия) и частично район, прилегающий к Верхнеудинску. М.С. Сафонов указывает, что боны принимались в платежи по номинальной их стоимости и сначала были приняты в Маймачене китайскими торговцами, видимо, потому, что наклеенные «керенки» отвечали за их подлинность, а потом уже русским населением Троицкосавска. Но впоследствии китайцы от приема «кяхтинок» отказались [11. С. 171]. Таким образом, из-за особенностей местной экономической жизни прием денежных суррогатов иностранными торговцами был своего рода «индикатором» платежного качества бон.

С осени 1918 г. Забайкалье полностью перешло под контроль антибольшевистских сил. Новая власть начала собственную политику в денежном обращении. В Омске в течение июля-сентября 1918 г. были созданы органы, координировавшие деятельность государственных кредитных учреждений, в том числе Центральное управление Государственного банка [12. С. 267]. Осознав бессмысленность игнорирования или запрета местных бон, «омское» Министерство финансов начало постепенный вывод денежных суррогатов (предварительно собрав с мест статистические сведения обо всех локальных эмиссиях). Именно благодаря этому шагу и делопроизводственным источникам, сохранившимся в фондах ГАРФ, стала возможной детализация событий, связанных с выпуском бон в Кяхте.

Интересна особенность: изъятие кяхтинских бон (в сравнении с другими локальными выпусками) началось достаточно поздно (видимо, из-за незначительности объема эмиссии). Вывод кяхтинских бон из обращения начался лишь с 1 июля 1919 г. по предписанию Минфина Российского правительства А.В. Колчака [10. Д. 105. Л. 65]. Циркулярное указание Омска было исполнено забайкальскими финансовыми органами. По нашим расчетам, основанным 
на количественных данных из работы М.С. Сафонова [11. С. 171] и отчетности Кяхтинского отделения Государственного банка, направленной в «омский» Минфин [10. Д. 120. Л. 32-37], кяхтинских бон на руках осталось весьма не много - всего порядка $12 \%$ от общего объема эмиссии (см. таблицу). В связи с этим сегодня эти боны весьма нечасто можно встретить в государственных и частных коллекциях; как правило они имеют сильные следы пребывания в обращении.

Известна судьба остатков неиспользованных бланков бон. После осуществления эмиссии они вместе с банковской гербовой печатью Кяхтинского отделения и клише подписей А.М. Малофеева и В.И. Ермоленко с июля 1918 г. в течение четырёх месяцев хранились в Кяхте в местном отделении Банка. 25 ноября 1918 г. огнеупорный ящик с чистыми бланками бон, банковской печатью и клише должностных лиц был вскрыт в присутствии комиссии, состоявшей из управляющего отделением Н.И. Шувалова, контролёра В.И. Ермоленко, кассира А.Д. Бруевича и представителя Троицкосавской городской управы городского головы А.И. Лушникова. По решению комиссии неиспользо- ванные бланки бон были уничтожены. Гербовая печать была направлена в банковское отделение. Клише подписи А.М. Малофеева 26 ноября 1918 г. было передано для хранения в городскую управу, а клише подписи В.И. Ермоленко было выдано ему на руки [Там же. Л. 120].

Курьезная эмиссия кяхтинских бон выполнила задачу по обеспечению текущей экономической жизни в Троицкосавском уезде в момент острого кризиса в денежном обращении. Она является примером весьма продуманной (хотя и вынужденной) финансовой меры региональных советских властей. Использование «керенок» в качестве основы для «обеспечения» бон позволило легко технически провести эмиссию, существенно облегчив ввод суррогатов в обращение. И то же самое обстоятельство вместе с небольшим объемом эмиссии позволили белогвардейским властям летом 1919 г. (в период изъятия из обращения «керенок» на белом Востоке России) безболезненно вывести из обращения кяхтинские боны (чего нельзя сказать о многих других денежных суррогатах Востока России, изъятие которых шло в тот же период).

\section{ЛИТЕРАТУРА}

1. Объяснительная записка к сводному балансу двадцати шести отделений Государственного банка с подотчётными казначействами на 1 мая 1919 г. // Вестник финансов, промышленности и торговли (Омск). 1919. № 14. С. 14-15.

2. Ходяков М.В. Деньги революции и Гражданской войны: денежное обращение в России. 1917-1920 гг. СПб. : Питер, 2009.224 с.

3. Исторический архив Омской области. Ф. 595. Оп. 1.

4. Российский государственный архив экономики. Ф. 2324. Оп. 3.

5. Аскарова Л.И., Лапенков В.М. Бумажные денежные знаки Иркутской области (1917-1997). Иркутск : Спарта, 1998. 201 с.

6. Наше денежное обращение : сборник материалов по истории денежного обращения в 1914-1925 гг. / под ред. Л.Н. Юровского. М. : Финансовое изд-во НКФ, 1926. 354 с

7. Рынков В.М. Финансовая политика антибольшевистских правительств Востока России (вторая половина 1918 - начало 1920 г.). Новосибирск : [Б. и.], 2006. 212 с.

8. Финансовое положение // Правительственный вестник (Омск). 1919. 6 фев.

9. Погребецкий А.И. Денежное обращение и денежные знаки Дальнего Востока за период Войны и Революции (1914-1924). Харбин : Изд-е Об-ва изучения Маньчжур. края и Дальневосточно-Сибирского общества «Книжное дело», 1924. 429 с.

10. Государственный архив Российской Федерации. Ф. Р-143. Оп. 7.

11. Сафонов М.С. Бонные эмиссии Прибайкалья 1918 г. // Советский коллекционер. 1930. № 7. С. $169-172$.

12. Петин Д.И. «Необходимость в образовании такового управления в настоящее время является крайне настоятельной...» : документы Исторического архива Омской области о создании Государственного Банка Сибири в 1918 г. // Новейшая история России. 2014. № 1. С. 265273.

Petin Dmitriy I. Omsk State Technical University (Omsk, Russia); Historical archive of Omsk region (Omsk, Russia). E-mail: dimario86@rambler.ru

\section{EMISSION OF MONEY SURROGATES BY SOVIET AUTHORITIES IN KIAKHTA IN SUMMER 1918.}

Keywords: The Civil War; the Soviet power; Kyakhta; currency; money surrogates; bonistika (notaphily).

The release of banknotes performed in a small town of the Trans-Baikal Kiakhta by decision of the local Soviet authorities in the summer of 1918 is an example of one of the most curious of the regional emissions of money surrogates during the Civil War in Russia. This money, since the 1920s, is well-known by experts in bonistics. Kyakhta bons are described in the scientific and popular writings on currency in the east of Russia during the Civil War. The main aim of this publication is to comprehensively analyze the history of monetary surrogates' emission by Soviet authorities in the summer of 1918 in Kyakhta on the basis of historical sources, newly identified by the author, as well as using the achievements of historiography. To achieve this aim it is necessary to complete the following tasks: Firstly, to identify common and specific features of currency on the territory of Siberia and Trans-Baikal, in particular, on the eve of the Civil War. Secondly, to indicate the reasons that caused the issue of Soviet bons in Kyakhta in the summer of 1918. Thirdly, to consider the procedure for the implementation of this emission and to reveal the features of using the bons. Fourthly, to analyze the Kyakhta bons' output procedure by the anti-Bolshevik authorities in the summer of 1919 and to represent further fate of bons. Fifthly, to solve the existing historiographical controversy associated with the beginning of the emission of Soviet bons in Kyakhta. The main source base of the study was the reporting documentation and records of Kyakhta branch of the State Bank, dating from the first half of 1919. These sources are stored in the State Archive of the Russian Federation in the fund of Central management of the State Bank of the Ministry of Finance of A.V. Kolchak's government. Supporting role plays the official correspondence by the manager of Kyakhta branch of the State Bank N.I. Shuvalov with the Division of banknotes of the State Bank, dated early 1918. This sources are deposited in the fund of the Ministry of Finance of the USSR in the Russian State Archive of Economics. The study revealed that contributions to this theme were made by finance historian A.I. Pogrebetskiy and collector M.S. Safonov. Subsequent works of Soviet and modern historians did 
not introduce anything new to the development of the emission and only cited the information from the works of A.I. Pogrebetskiy. On the basis of unpublished sources the author eliminated inconsistencies of historiography. In particular, it was concluded that the work by M.S. Safonov about the emission of Kyakhta bons is the most complete up to nowadays. In addition, thanks to the introduction into circulation of new sources the reasons for the beginning of a local emission were identified, the course of the preparation and implementation of monetary surrogates' issue was presented, the fate of Kyakhta bons was traced. All statistical and analytical material on the history of Kyakhta emissions are summarized in tabular form. According to the author of the publication, curious emission of bons in Kyakhta in summer of 1918 is an example of a very well thought-out (albeit involuntary) financial measure of the regional Soviet authorities.

\section{REFERENCES}

1. Anon. (1919) Ob"yasnitel'naya zapiska k svodnomu balansu dvadtsati shesti otdeleniy Gosudarstvennogo banka s podotchetnymi kaznacheystvami na 1 maya $1919 \mathrm{~g}$. [Explanatory note to the consolidated balance sheet of twenty-six branches of the State Bank with accountable treasuries as of May 1, 1919]. Vestnik finansov, promyshlennosti i torgovli. 14. pp. 14-15.

2. Khodyakov, M.V. (2009) Den'gi revolyutsii i Grazhdanskoy voyny: denezhnoe obrashchenie v Rossii. 1917-1920 gg. [The money of the Revolution and the Civil War: Money circulation in Russia. 1917-1920]. St. Petersburg: Piter.

3. Historical Archive of Omsk Region. Fund 595. List 1.

4. The Russian State Archive of Economics. Fund 2324. List 3.

5. Askarova, L.I. \& Lapenkov, V.M. (1998) Bumazhnye denezhnye znaki Irkutskoy oblasti (1917-1997) [Paper banknotes of Irkutsk region (19171997)]. Irkutsk: Sparta.

6. Yurovskogy, L.N. (1926) Nashe denezhnoe obrashchenie: Sbornik materialov po istorii denezhnogo obrashcheniya v 1914-1925 gg. [Our monetary circulation: A collection of materials on the history of monetary circulation in 1914-1925]. Moscow: Finansovoe izd-vo NKF.

7. Rynkov, V.M. (2006) Finansovaya politika antibol'shevistskikh pravitel'stv vostoka Rossii (vtoraya polovina 1918 - nachalo 1920 g.) [Financial policy of the anti-Bolshevik governments of the east of Russia (the second half of 1918s - early 1920s)]. Novosibirsk: [s.n.].

8. Anon. (1919) Finansovoe polozhenie [Financial situation]. Pravitel'stvennyy vestnik. 6th February.

9. Pogrebetskiy, A.I. (1924) Denezhnoe obrashchenie i denezhnye znaki Dal'nego Vostoka za period Voyny i Revolyutsii (1914-1924) [Money circulation and currency notes of the Far East for the period of War and Revolution (1914-1924)]. Kharbin: Knizhnoe delo.

10. The State Archives of the Russian Federation. Fund R-143. List 7.

11. Safonov, M.S. (1930) Bonnye emissii Pribaykal'ya 1918 g. [Bons emission in Baikal region in 1918]. Sovetskiy kollektsioner. 7. pp. 169-172.

12. Petin, D.I. (2014) State Bank of Siberia Establishment in 1918 (based on the documents from Omsk region Historical Archive). Noveyshaya istoriya Rossii-Modern History of Russia. 1. pp. 265-273. (In Russian). 